\title{
Findings About Events or Interventions Reason Not Done
}

National Cancer Institute

\section{Source}

National Cancer Institute. Findings About Events or Interventions Reason Not Done. NCI

Thesaurus. Code C113366.

The explanation given as to why findings about events or interventions were not collected. 